\title{
Qualidade e vida útil pós-colheita dos frutos de melão submetidos a diferentes
}

\section{lâminas de irrigação}

\author{
Quality and postharvest shelf life of melon fruits subjected to different irrigation depths \\ Calidad y vida útil poscosecha de frutos de melón sometidos a diferentes profundidades de riego
}

Recebido: 23/12/2021 | Revisado: 30/12/2021 | Aceito: 15/01/2022 | Publicado: 17/01/2022

\author{
Manoel Valnir Júnior \\ ORCID: https://orcid.org/0000-0001-7794-2184 \\ Instituto Federal de Educação, Ciência e Tecnologia do Ceará, Brasil \\ E-mail: valnir@ifce.edu.br \\ Vera Lúcia Antunes de Lima \\ ORCID: https://orcid.org/0000-0001-7495-6935 \\ Universidade Federal de Campina Grande, Brasil \\ E-mail: antuneslima@gmail.com \\ Raimundo Rodrigues Gomes Filho \\ ORCID: https://orcid.org/0000-0001-5242-7581 \\ Universidade Federal de Sergipe, Brasil \\ E-mail: rrgomesfilho@ hotmail.com \\ Clayton Moura de Carvalho \\ ORCID: https://orcid.org/0000-0002-4382-5382 \\ Instituto Federal de Educação, Ciência e Tecnologia Baiano, Brasil \\ E-mail: Clayton.carvalho@ifbaiano.edu.br \\ Sílvio Carlos Ribeiro Vieira Lima \\ ORCID: https://orcid.org/0000-0003-4852-2222 \\ Secretaria do Desenvolvimento Econômico e Trabalho do Estado do Ceará, Brasil \\ E-mail: silviocarlos@yahoo.com.br \\ João Paulo Alves da Rocha \\ ORCID: https://orcid.org/0000-0003-4081-3332 \\ Instituto Federal de Educação, Ciência e Tecnologia Goiano, Brasil \\ E-mail: j.paulo25ipueis@gmail.com
}

\begin{abstract}
Resumo
Para a produção de melão atender aos padrões exigidos pelo mercado é necessário uso de tecnologias que possibilitem amenizar o efeito de fatores limitantes ao desenvolvimento das culturas. A irrigação, além de ser uma dessas tecnologias é apontada como uma das alternativas para o desenvolvimento socioeconômico de regiões semiáridas. Entretanto, esta deve ser manejada adequadamente, a fim de evitar problemas de degradação dos recursos hídricos e edáficos. Mediante o exposto, objetivou-se analisar o comportamento da cultura do melão sob diferentes regimes hídrico no solo. O experimento foi desenvolvido em área particular no Distrito de Irrigação do Baixo Acaraú, utilizando-se sementes de melão, var. inodorus, cv. F1 10/00 do tipo "amarelo", irrigadas com diferentes lâminas de irrigação. As sementes foram plantadas em fileiras equidistantes em $2 \mathrm{~m}$ colocando-se duas sementes por emissor distanciadas entre si de aproximadamente $12 \mathrm{~cm}$, totalizando 24 plantas por fileira. As plantas foram irrigadas com um sistema localizado tipo gotejamento, com emissores de vazão de $2,3 \mathrm{~L} \mathrm{~h}^{-1}$, espaçados de $0,5 \mathrm{~m}$. A quantidade de água aplicada foi determinada mediante a necessidade de reposição das perdas decorrentes da evapotranspiração da cultura (ETc). Avaliou-se a vida útil pós-colheita (perda de peso, brix e firmeza da polpa). Verificou-se que as diferentes lâminas fornecidas no ciclo influenciaram as características de pós-colheita peso, brix e textura dos frutos, no entanto, as lâminas de irrigação causavam efeitos para mais nas características peso e brix à medida que este era aumentado, exceto para variável textura do fruto.
\end{abstract}

Palavras-chave: Cucumis melo; Evapotranspiração; Qualidade dos frutos; Manejo de irrigação; Meloeiro.

\begin{abstract}
For melon production to meet the standards required by the market, it is necessary to use technologies that make it possible to alleviate the effect of limiting factors on crop development. Irrigation, in addition to being one of these technologies, is identified as one of the alternatives for the socioeconomic development of semiarid regions. However, this must be properly managed in order to avoid problems of degradation of water and edaphic resources. Based on the above, the objective was to analyze the behavior of the melon crop under different soil water regimes. The experiment was carried out in a private area in the Baixo Acaraú Irrigation District, using melon seeds, var. inodorus, cv. F1 10/00 "yellow" type, irrigated with different irrigation depths. The seeds were planted in rows equidistant at 2 $\mathrm{m}$, placing two seeds per emitter spaced approximately $12 \mathrm{~cm}$ apart, totaling 24 plants per row. The plants were irrigated with a localized drip system, with $2.3 \mathrm{~L} \mathrm{~h}-1$ flow emitters, spaced $0.5 \mathrm{~m}$ apart. The amount of water applied
\end{abstract}


was determined by the need to replace losses resulting from crop evapotranspiration (ETc). Postharvest shelf life (weight loss, brix and pulp firmness) was evaluated. It was found that the different blades provided in the cycle influenced the postharvest characteristics of fruit weight, brix and texture, however, the irrigation blades caused more effects on the weight and brix characteristics as it was increased, except for variable texture of the fruit.

Keywords: Cucumis melo; Evapotranspiration; Fruit quality; Irrigation management; Melon.

\begin{abstract}
Resumen
Para que la producción de melón cumpla con los estándares exigidos por el mercado, es necesario utilizar tecnologías que permitan paliar el efecto de los factores limitantes en el desarrollo del cultivo. El riego, además de ser una de estas tecnologías, se identifica como una de las alternativas para el desarrollo socioeconómico de las regiones semiáridas. Sin embargo, esto debe gestionarse adecuadamente para evitar problemas de degradación de los recursos hídricos y edáficos. Con base en lo anterior, el objetivo fue analizar el comportamiento del cultivo de melón bajo diferentes regímenes hídricos del suelo. El experimento se llevó a cabo en un área privada del Distrito de Riego de Baixo Acaraú, utilizando semillas de melón, var. inodoro, cv. F1 10/00 tipo "amarillo", regado con diferentes profundidades de riego. Las semillas se sembraron en hileras equidistantes a $2 \mathrm{~m}$, colocando dos semillas por emisor espaciadas aproximadamente a $12 \mathrm{~cm}$, totalizando 24 plantas por hilera. Las plantas se regaron con un sistema de goteo localizado, con emisores de flujo de 2,3 L h-1, espaciados 0,5 m. La cantidad de agua aplicada fue determinada por la necesidad de reponer las pérdidas resultantes de la evapotranspiración del cultivo (ETc). Se evaluó la vida útil poscosecha (pérdida de peso, grados brix y firmeza de la pulpa). Se encontró que las diferentes hojas proporcionadas en el ciclo influyeron en las características poscosecha de peso, brix y textura del fruto, sin embargo, las hojas de riego causaron más efectos en las características de peso y brix a medida que se incrementó, excepto por la textura variable de la fruta.
\end{abstract}

Palabras clave: Cucumis melo; Evapotranspiración; Calidad de la fruta; Gestión de riego; Melón.

\title{
1. Introdução
}

O melão (Cucumis melo L.) é uma planta cujos frutos têm grande expressão econômica e social no Brasil, principalmente para a região Nordeste que concentra cerca de 95\% da produção nacional, com destaque aos estados do Rio Grande do Norte, Ceará, Bahia e Pernambuco (Barros et al., 2019; Pinto et al., 2019; Pereira et al., 2021). e que apresenta condições favoráveis ao seu cultivo, como altos níveis de radiação e temperatura e baixa precipitação e umidade relativa do ar, juntamente com a ausência de mosca-das-frutas (Queiroga et al., 2020).

Segundo Valnir Júnior et al. (2013), o Nordeste possui condições edafoclimáticas, exceto pluviosidade, favoráveis, como temperatura, luminosidade e umidade relativa do ar adequados ao crescimento e à produção de muitas olerícolas, inclusive o melão. Por ser cultivada no período seco, a irrigação é prática limitante ao sistema de produção comercial da cultura e seu manejo apresenta-se como um dos fatores indispensáveis para o avanço e sucesso na produção da cultura do melão, tanto na produtividade como na qualidade dos frutos.

Sem dúvida os baixos índices pluviométricos e as altas taxas de evapotranspiração representam um grande entrave ao desenvolvimento agrícola do semiárido brasileiro e a irrigação apresenta-se como uma alternativa fundamental para superar a escassez de água e permitir ganhos na produção (Campelo et al., 2014; Simões et al., 2018).

No cultivo do melão, a irrigação é promovida predominantemente pelo sistema de gotejamento, por evitar molhar a parte aérea da planta, permitir maior controle na quimigação e maior eficiência de uso da água (Pereira et al., 2017; Guimarães et al., 2020; Pereira et al., 2021). Para a cultura do meloeiro é necessário a utilização de práticas de manejo que visem a otimização da aplicação de água por meio da lâmina de irrigação mais adequada em cada fase fenológica da mesma e sua frequência de aplicação (Melo et al., 2011; Valnir Júnior et al., 2013; Simões et al., 2018).

Mediante o exposto, objetivou-se com este trabalho estudar o efeito de diferentes lâminas de irrigação nas variáveis de pós-colheita do meloeiro.

\section{Metodologia}

O experimento foi instalado e conduzido em área particular no Distrito de Irrigação do Baixo Acaraú pertencente ao 
DNOCS e situado na região norte do Estado do Ceará, com as coordenadas geográficas $03^{\circ} 05^{\prime} 20^{\prime}$ de latitude Sul e 4003'37" de longitude Oeste do meridiano de Greenwich, e 56,08 $\mathrm{m}$ de altitude.

O clima da região é, conforme a classificação de Thornthwaite \& Mather (1955), do tipo Aw Tropical Chuvoso, que representa clima quente, com precipitação média anual de $900 \mathrm{~mm}$, concentradas nos meses de janeiro a junho, temperaturas: mínima, média e máxima anual de $22,8{ }^{\circ} \mathrm{C}, 28,1^{\circ} \mathrm{C}$ e $34,7{ }^{\circ} \mathrm{C}$, respectivamente. Insolação de $2.650 \mathrm{~h}$ ano ${ }^{-1}$, umidade relativa média anual de $70 \%$, velocidade média dos ventos de $3 \mathrm{~m} \mathrm{~s}^{-1}$ e evaporação média anual de $1.600 \mathrm{~mm}$. Os solos predominantes são da classe dos Podzólicos, Latossolos e Areias Quartzosas, apresentando textura média ou média/leve, muito permeáveis, bem drenados e profundos.

No experimento foram utilizadas sementes de melão (Cucumis melo L), originadas da Petoseed®, var. inodorus, cv. F1 10/00 do tipo "amarelo", caracterizado por apresentar alta produtividade, polpa branco-creme, tolerância a raça 1 de oídio, folhas largas, boa cobertura dos frutos, sendo estes elípticos, com casca levemente enrugada, cavidade interna pequena, uniforme, com ${ }^{\circ}$ Brix entre 10 e $12^{\circ}$ e ciclo relativamente curto (entre 64 e 66 dias) se plantado nas condições climáticas do Nordeste. Bastante difundido na região, sendo à época a mais cultivada e exportada pelos produtores locais.

Na Tabela 1 estão os parâmetros físico-hídricos determinados para as profundidades de 0,15, 0,25, 0,45 e 0,55 m da superfície do solo. Já na Tabela 2 temos a caracterização química do solo para as camadas de 0,00 - 0,20 e 0,20 - 0,40 m de profundidade, a partir de amostras compostas (cada uma a partir de 10 amostras simples distribuídas aleatoriamente na área) retiradas do campo nas referidas camadas. Estas análises foram realizadas no laboratório de Solos e Água do Departamento de Ciências do Solo da Universidade Federal do Ceará em convênio com a Fundação Cearense de Meteorologia e Recursos hídricos - FUNCEME, Fortaleza, CE, conforme metodologias propostas por EMBRAPA (1997).

Tabela 1. Caracterização físico-hídrica do solo da área experimental.

\begin{tabular}{|c|c|c|c|c|c|}
\hline \multirow{2}{*}{ Parâmetro } & \multirow{2}{*}{ Unidade } & \multicolumn{4}{|c|}{ Profundidade $(\mathrm{m})$} \\
\hline & & 0,15 & 0,25 & 0,45 & 0,55 \\
\hline Areia Grossa & $\mathrm{g} \mathrm{kg}^{-1}$ & 690 & 730 & 710 & 610 \\
\hline Areia Fina & $\mathrm{g} \mathrm{kg}^{-1}$ & 250 & 220 & 220 & 310 \\
\hline Silte & $\mathrm{g} \mathrm{kg}^{-1}$ & 40 & 30 & 40 & 40 \\
\hline Argila & $\mathrm{g} \mathrm{kg}^{-1}$ & 20 & 20 & 30 & 40 \\
\hline Argila Natural & $\mathrm{g} \mathrm{kg}^{-1}$ & 10 & 10 & 20 & 20 \\
\hline Densidade do Solo & $\mathrm{g} \mathrm{cm}^{-3}$ & 1,36 & 1,42 & 1,39 & 1,38 \\
\hline Densidade das Partículas & $\mathrm{g} \mathrm{cm}^{-3}$ & 2,66 & 2,61 & 2,62 & 2,62 \\
\hline Porosidade total & $\%$ & 49 & 46 & 47 & 47 \\
\hline Capacidade de Campo* & g $100 \mathrm{~g}^{-1}$ & 1,82 & 1,48 & 1,80 & 1,90 \\
\hline Ponto de Murcha Permanente* & $\mathrm{g} 100 \mathrm{~g}^{-1}$ & 1,62 & 1,13 & 1,50 & 1,24 \\
\hline Água disponível & $\mathrm{g} 100 \mathrm{~g}^{-1}$ & 0,20 & 0,35 & 0,30 & 0,66 \\
\hline Classe textural & & Areia & Areia & Areia & Areia \\
\hline
\end{tabular}

* As umidades na capacidade de campo e ponto de murcha permanente foram determinadas nos potenciais de $-33 \mathrm{kPa}$ e $-1500 \mathrm{kPa}$, respectivamente. Fonte: Autores. 
Tabela 2. Caracterização química do solo da área experimental.

\begin{tabular}{|c|c|c|c|}
\hline \multirow[b]{2}{*}{ Parâmetro } & \multirow[b]{2}{*}{ Unidade } & \multicolumn{2}{|c|}{ Camada (m) } \\
\hline & & $0,00-0,20$ & $\begin{array}{r}0,20- \\
0,40\end{array}$ \\
\hline Matéria Orgânica & $\mathrm{g} \mathrm{kg}^{-1}$ & 3,67 & 1,22 \\
\hline Cálcio & cmolc dm ${ }^{-3}$ & 1,30 & 1,10 \\
\hline Magnésio & cmolc $\mathrm{dm}^{-3}$ & 1,20 & 1,00 \\
\hline Cálcio + Magnésio & cmolc dm $\mathrm{dm}^{-3}$ & 2,50 & 2,10 \\
\hline Alumínio & cmolc dm $\mathrm{dm}^{-3}$ & 0,00 & 0,00 \\
\hline Potássio & $\mathrm{mg} \mathrm{dm}{ }^{-3}$ & 27,00 & 17,00 \\
\hline Fósforo & $\mathrm{mg} \mathrm{dm}{ }^{-3}$ & 1,00 & 1,00 \\
\hline Sódio & $\mathrm{mg} \mathrm{dm}^{-3}$ & 3,00 & 2,00 \\
\hline Ferro & ppm & 3,40 & 4,10 \\
\hline Cobre & ppm & 0,20 & 0,10 \\
\hline Zinco & ppm & 0,50 & 0,50 \\
\hline Manganês & ppm & 3,80 & 3,80 \\
\hline Condutividade elétrica & $\mathrm{dS} \mathrm{m}^{-1}$ & 0,08 & 0,07 \\
\hline $\mathrm{pH}$ & & 6,10 & 6,00 \\
\hline
\end{tabular}

Fonte: Autores.

Os resultados da análise química serviram de base às adubações de fundação e de cobertura ao longo do ciclo da cultura.

Para as amostras de solos coletadas nas profundidades de 0,15, 0,25, 0,45 e 0,55 $\mathrm{m}$ foram obtidas as curvas características de retenção d'água no solo, utilizando a câmara de pressão de Richards et al. (1956), através da aplicação de valores de pressão variando de $-10 \mathrm{kPa}$ a $-1500 \mathrm{kPa}$, sendo estes limites representativos da umidade na capacidade de campo e no ponto de murcha, respectivamente.

O preparo do solo constou de uma aração, uma gradagem para destorroamento do solo, abertura dos sulcos e confecção dos camalhões de plantio com grade enleiradeira na faixa de solo onde foram inseridas as fileiras de plantas.

Por já existir uma área com um plantio de banana no lado dos ventos dominantes da área experimental, plantou-se somente uma linha contínua de sorgo concomitante ao plantio do melão, com objetivo de criar um quebra vento, haja vista, estarem os demais lados do plantio cercados pela mata nativa.

O plantio foi feito em fileiras equidistantes em $2 \mathrm{~m}$ e os emissores espaçados de 0,50 $\mathrm{m}$ colocando-se duas covas por emissor distanciadas entre si de aproximadamente $0,25 \mathrm{~m}$, cada cova continha uma semente a uma profundidade de, aproximadamente, 2 a $3 \mathrm{~cm}$, totalizando 4 plantas por metro linear. Este espaçamento era comumente utilizado em áreas de produção do referido Distrito e resulta em uma população de planta de 20.000 plantas ha-1.

As plantas cresceram naturalmente, ou seja, sem nenhuma interferência no sistema de condução de ramos ou desbrotas. E aos 47 dias após semeadura (DAS) as linhas de irrigação foram distanciadas, ficando em torno de 0,10 m do pé da planta, como forma de amenizar a ação do cancro, bastante beneficiado pela combinação: temperaturas altas e umidade elevada do solo.

O controle de plantas invasoras deu-se de forma a evitar competições com a cultura do melão sendo as mais frequentes o capim, a beldroega, além de outras. Logo aos seis dias após o plantio foi feita uma retirada manual de ervas daninhas, especialmente na área do bulbo molhado. Vinte e dois dias após, fez-se uma capina com auxílio de enxada.

Aos 54 DAS procedeu-se a viragem dos frutos nos três blocos, fazendo giros leves, com a finalidade de expor toda a superfície do fruto à mesma luminosidade, evitando desta forma, a formação de "barriga branca" ou mancha de encosto.

As ações fitossanitárias foram de caráter preventivo e/ou curativo, com especial atenção para os agentes: mosca 
branca (Bemisia argentifolli), lagarta minadora (Liriomyza sativae) e broca-das-cucurbitáceas (Diaphania nitidalis sp.) pelas pertinentes ocorrências e potencial de danos econômicos à cultura do melão na região. Dentre as doenças tiveram incidência ao longo do ciclo as fúngicas cancro das hastes (Didymella bryoniae) e o míldio (Pseudoperonospora cubensis), as pulverizações eram feitas preferencialmente no período da manhã, como forma de amenizar a ocorrência de morte de insetos polinizadores bem como, diminuir os efeitos nocivos ao aplicador com a manipulação dos agroquímicos.

Adotou-se o sistema de irrigação localizado tipo gotejamento, com emissores na linha, da PLASTO®, modelo Hidrodrip II, trabalhando a uma pressão média de $150 \mathrm{kPa}$ e vazão nominal de 2,3 $\mathrm{L} \mathrm{h}^{-1}$, espaçados de $0,5 \mathrm{~m}$, resultando em um emissor para cada duas plantas, a uma distância de 0,10 m caule. Os emissores foram previamente avaliados em condições de laboratório e no campo, sob condições normais de operação.

A condução d'água às plantas foi composta de linhas laterais espaçadas em $2 \mathrm{~m}$, de polietileno, diâmetro nominal 16 $\mathrm{mm}$, PN $250 \mathrm{kPa}$ e $38 \mathrm{~m}$ de comprimento. Abastecidas por linhas secundárias de polietileno de $20 \mathrm{~mm}, \mathrm{PN} 400 \mathrm{kPa}$ e linha principal de PVC soldável de $50 \mathrm{~mm}$, PN $400 \mathrm{kPa}$ nos comprimentos máximos de $56 \mathrm{~m}$ e $94 \mathrm{~m}$, respectivamente. O sistema constou ainda, de um filtro de disco de 120 mesh da marca AMIAD® de 1 1⁄2 polegadas, seis válvulas reguladoras de pressão de 3/4 polegadas, sendo duas para cada bloco, e todo o conjunto era alimentado através de uma redução feita na adutora de 100 mm existente na área, obtendo-se assim, a pressão necessária para o funcionamento adequado do mesmo. A pressão de serviço, em todo experimento, para todos os tratamentos foi mantida a $150 \mathrm{kPa}$, monitorada por um manômetro instalado na entrada d'água no sistema, aferido anteriormente ao experimento.

A quantidade de água aplicada foi determinada mediante a necessidade de reposição das perdas decorrentes da evapotranspiração da cultura (ETc), levando-se em conta a irrigação pontual. Sendo a estimativa da evapotranspiração de referência (ETo) feita a partir de leituras diretas da evaporação diária através de um tanque evaporímetro Classe "A". É oportuno ressaltar que a utilização do método do tanque Classe "A", embora menos preciso do que os métodos diretos de estimativa da evapotranspiração como no caso dos lisímetros, justifica-se pela simplicidade de seu uso e por estar disponível à época aos técnicos e irrigantes do Distrito. Os níveis d'água aplicados nos tratamentos eram independentes e controlados por registros de linha, conforme o tempo de irrigação.

Os tratamentos foram compostos a partir de cinco lâminas de irrigação: L1 (0,6); L2 (0,8); L3 (1,0); L4 (1,2); e, L5 (1,4 da Evapotranspiração da Cultura nos sistemas localizados (ETcL)).

O plano de manejo da irrigação foi pautado na estimativa da evapotranspiração de referência (ETo), basilar no cálculo da ETc. Para tanto utilizou-se a fórmula:

$$
\mathrm{ETo}=\mathrm{ECA} . \mathrm{Kp}
$$

Em que: ETo: evapotranspiração de referência (mm dia-1); ECA: evaporação do tanque (mm dia ${ }^{-1}$ ); e Kp: coeficiente do tanque.

Muito embora, sabendo-se que o valor do coeficiente do tanque Kp é decorrente da combinação dos fatores umidade relativa do ar, bordadura do tanque e velocidade do vento, na impossibilidade de obtenção deste último, adotou-se um valor fixo de $\mathrm{Kp}$ de 0,72, em virtude dos fortes ventos apresentados e das altas temperaturas observadas no local do experimento, concordando com Andrade Júnior et al. (1991), ao relatarem que para regiões de clima semiárido, o Kp pode variar de 0,70 até 0,75, aproximando-se mais do primeiro sempre que estas características forem elevadas.

A expressão utilizada no cálculo da evapotranspiração da cultura no local (ETcL) para a irrigação localizada foi:

$$
\mathrm{ETcL}=\mathrm{ETo} . \mathrm{Kc} . \mathrm{FCS}
$$

Em que: ETcL: evapotranspiração da cultura no local (mm dia-1); Kc: coeficiente da cultura; e FCS: fator de cobertura do solo. Os dados agrometeorológicos que serviram de base à condução da pesquisa foram oriundos de equipamentos 
instalados na área experimental como tanque Classe "A", pluviômetros, medidores de temperatura do ar e do solo. Estes últimos forneciam valores diários de temperatura máxima e mínima do ar e através de termômetros de solo instalados às profundidades verticais de $15 \mathrm{~cm}$ tínhamos as temperaturas do solo. Em todos os equipamentos as leituras eram feitas até as 8:00 h da manhã.

Em decorrência da falta de valores de coeficientes de cultivo Kc do meloeiro específicos para o Distrito de Irrigação, adotou-se os valores médios de 0,50, 0,80, 1,0 e 0,70, recomendados por Doorenbos \& Kassam (1994) e Doorenbos \& Pruitt (1997), referentes aos períodos de desenvolvimento vegetativo, floração, frutificação e maturação, respectivamente.

O fator de cobertura do solo FCS ou fator de sombreamento foi calculado segundo recomendações de Hernandez (1995), o qual preconiza medir com régua milimetrada, as dimensões dos ramos do meloeiro no sentido transversal às linhas de plantio, dividindo o valor encontrado pelo espaçamento da cultura entre fileiras de plantas.

Na pesquisa optou-se em fazer as medições nas parcelas de tratamentos L3, ou 100\% da ETcL, considerada lâmina padrão, em períodos alternados de 7 dias. A escolha do tratamento se deu devido ser o que melhor se assemelha a situação operacional existente no Distrito.

O tempo de aplicação de água baseou-se nos conceitos da necessidade de reposição hídrica à cultura, em consonância com a hidráulica do sistema localizado, gerando uma planilha específica de operacionalização das irrigações desenvolvida no sistema Excel (planilha própria), que fornecia o tempo de irrigação em minuto.

O tempo de aplicação d'água, utilizado na diferenciação dos tratamentos adotados, de acordo com o nível de irrigação, foi determinado pela seguinte expressão.

$$
T_{\text {IRRIGAÇÂOO }}=\frac{\left[\frac{\left(\frac{B T c_{L} F_{L} A_{p \cdot 60}}{q_{\text {gotejador }}}\right)}{E f}\right]}{N_{\text {gotejadores }}}
$$

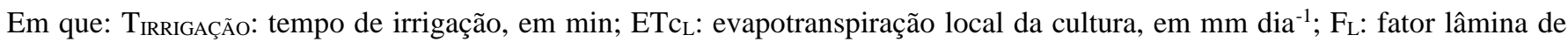
irrigação $\left(0,6,0,8,1,0,1,2\right.$ e 1,4 da $\left.\mathrm{ETc}_{\mathrm{L}}\right)$; AP: área ocupada pela planta, em m²; qgotejador: vazão do gotejador, em $\mathrm{L} \mathrm{h}^{-1}$; Ef: eficiência do sistema; e N: número de gotejadores.

Os valores da vazão do gotejador por planta, a eficiência do sistema de aplicação (95\%), o número de gotejadores por planta, área ocupada por planta $\left(0,5 \mathrm{~m}^{2}\right)$ e os fatores de desenvolvimento da planta $(\mathrm{Kc})$ foram inerentes à hidráulica do sistema e à cultura utilizada. Durante o período de aplicação dos tratamentos não houve precipitações.

As lâminas de irrigação decorrentes da necessidade evapotranspirométrica da cultura (ETc) em cada tratamento eram confirmadas pela tensão em que a água estava retida nas partículas do solo (potencial mátrico) e da dinâmica de água no perfil de interesse $(0,55 \mathrm{~m})$.

Para monitorar estes fatores optou-se por instalar, na lâmina de irrigação padrão (100\% da ETc) de cada bloco, uma bateria de tensiômetro, resultando para toda área experimental doze baterias contendo cada, quatro tensiômetros nas distâncias verticais de $0,15,0,25,0,45$ e $0,55 \mathrm{~m}$, totalizando 48 medidores de tensão, radialmente distribuídos a 0,10 m em relação à planta. As leituras foram feitas diariamente até às 8 horas e antes do início da irrigação.

A média das leituras dos tensiômetros instalados a $0,15 \mathrm{~m}$ de profundidade indicativa de que a lâmina aplicada atendeu ao valor de tensão d'água no solo de - $30 \mathrm{kPa}$, considerado crítico para o meloeiro. Tanto os tensiômetros instalados a 0,15 m como nas demais profundidades, serviram para quantificar a água armazenada no solo, e sua correlação entre a água aplicada e a demanda evaporativa da cultura.

As leituras fornecidas pelos tensiômetros em valor de potencial mátrico $(\psi \mathrm{m})$ da água no solo eram transformadas de 
acordo com a descrição a seguir:

$$
\psi \mathrm{m}=-12,6(\mathrm{AHg})+\mathrm{Ac}+\mathrm{Ai}
$$

Em que: $\psi$ m: potencial mátrico de água no solo (cm.c.a); AHg: altura da coluna de mercúrio (cm); Ac: altura da cuba de mercúrio a superfície do solo $(\mathrm{cm})$; e Ai: altura de instalação do tensiômetro $(\mathrm{cm})$.

Em virtude da baixa fertilidade e da classe textural arenosa da maioria dos solos do Distrito de Irrigação, confirmado na análise do solo da área experimental (Tabelas 1 e 2) a adubação de fundação constou da incorporação, por ocasião do preparo do solo para o plantio, do equivalente a $18.000 \mathrm{~kg} \mathrm{ha}^{-1}$ de esterco bovino e $1.562,50 \mathrm{~kg} \mathrm{ha}^{-1} \mathrm{de}$ calcário dolomítico (PRNT de 67\%), prática muito utilizada na região.

Devido a problemas no fornecimento do adubo granulado MAP (Monoamôniofosfato), este só foi aplicado aos 8 DAS na quantidade de $360 \mathrm{~kg} \mathrm{ha}^{-1}$, ou seja, $20 \mathrm{~g}$ por cova, o que corresponde a 360 x $0,11 \mathrm{~kg} \mathrm{de} \mathrm{N} \mathrm{ha}^{-1}$ e 360 x 0,48 de $\mathrm{P}_{2} \mathrm{O}_{5} \mathrm{ha}^{-1}$.

As adubações eram realizadas manualmente fazendo entre as plantas uma fenda onde se colocava o adubo e cobria com a areia removida. As quantidades totais afora a fundação (cobertura) e a aplicação do MAP foram: Nitrogênio $=58 \mathrm{~kg} \mathrm{ha}$ ${ }^{1}$; Potássio $=188 \mathrm{~kg} \mathrm{ha}^{-1}$, nas formas de uréia e sulfato de potássio, respectivamente, aplicados em duas vezes iguais uma aos 25 dias e a outra aos 40 DAS.

Com intuito de melhorar a qualidade e resistência do fruto pós-colheita optou-se em aplicar ao longo do ciclo e de forma foliar, o composto WUXAL, cálcio em suspensão, na quantidade total em toda a área efetiva de $280 \mathrm{~mL}$.

No experimento foram realizadas três colheitas em intervalos não equidistantes e sempre que os frutos atingiam o ponto de maturação fisiológica que para a variedade era representado pela coloração amarelo intenso e teor de açúcar em torno de $12{ }^{\circ}$ Brix, obtido com auxílio de um refratômetro digital portátil. A primeira colheita ocorreu no $66^{\circ}$ dia após a semeadura (DAS), sete dias depois foi realizada a segunda e três dias após esta a terceira e última colheita, com a retirada completa de todos os frutos.

Ao término da primeira colheita, foram amostrados dois frutos, por parcela, um para análise no dia da colheita e o outro 30 dias depois (vida útil pós-colheita) seguindo metodologia adotada por Mendonça et al. (2004). As análises laboratoriais foram realizadas com a finalidade de se obter os teores de sólidos solúveis totais ( ${ }^{\circ}$ Brix), firmeza da polpa e perda de peso. As avaliações foram realizadas no Laboratório de Irrigação da Faculdade de Tecnologia Centec - Sobral do Instituto Centro de Ensino Tecnológico - CENTEC.

$\mathrm{Na}$ seleção dos frutos teve-se cuidados em não escolher os portadores de imperfeições, facilmente detectáveis (ferimentos mecânicos, rachaduras, atacados por patógenos, etc.).

Os testes de sólidos solúveis totais foram feitos com os frutos completamente maduros, onde foi retirada uma fatia longitudinal de aproximadamente $3 \mathrm{~cm}$ de espessura, sem casca e sem sementes, sendo parte desta colocada em um liquidificador para homogeneizar a amostra e em seguida determinou-se o ${ }^{\circ}$ Brix, utilizando um refratômetro digital, com correção automática de temperatura.

Já os testes que especificam a firmeza da polpa (textura), foram realizados com auxílio de um penetrômetro manual com pluger de $8 \mathrm{~mm}$ de diâmetro, a partir de frutos previamente seccionados longitudinalmente em quatro partes (fatias) eqüidistantes, sendo a medida feita na posição mediana da face lateral de, pelo menos, duas fatias. As leituras em libras (lb) foram convertidas em Newton $(\mathrm{N})$, multiplicando o valor encontrado pelo fator 4,45 (Filgueiras et al., 2000), onde $1 \mathrm{~N}$ corresponde a 1 libra x 4,445 (McCollum, et al., 1989).

Os frutos selecionados foram analisados após permanência em prateleira sob temperatura ambiente em torno de 28 0C, e umidade relativa do ar variando de 70 a $80 \%$ nos 30 dias de armazenamento. A análise de perda de peso foi mediante ao cálculo da diferença do peso inicial do fruto, momento em que iniciou a contagem do tempo e aquele obtido 30 dias depois 
(Costa, 1999).

\section{Resultados e Discussão}

Após 30 dias de armazenamento a perda de peso dos frutos das plantas irrigadas com a lâmina de $372,38 \mathrm{~mm}$ foi 120,60\% maior que os das plantas irrigadas com uma lâmina de 159,41 mm (Figura 1).

Figura 1. Perda de peso dos frutos do meloeiro var. inodoro do tipo "amarelo" cultivar híbrida F1 10/00 em função das lâminas de irrigação.

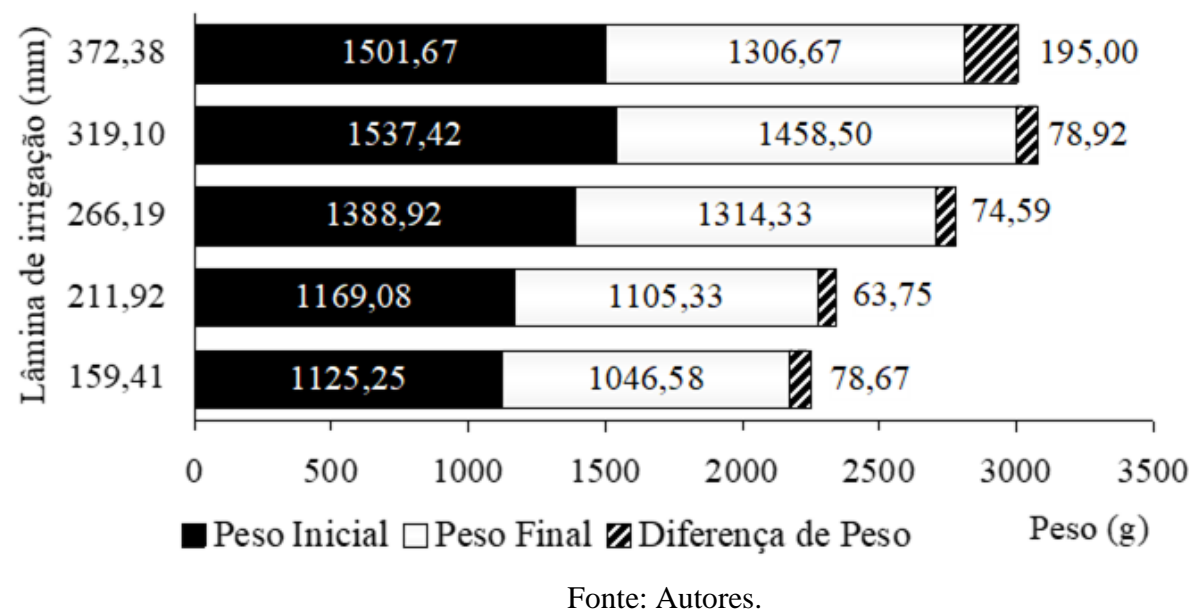

As diferenças observadas na perda de peso dos frutos estudados durante os 30 dias de armazenamento eram maiores à medida que era aumentada a água aplicada, variando de 6,99\% (78,67 g) na menor lâmina $(159,41 \mathrm{~mm})$ para 53,08\% (195,00 g) para a maior lâmina estudada (Figura 1), exceto para as lâminas L2 (211,92 mm) e L3 (266,19 mm).

A maior perda de peso verificada na lâmina de $372,38 \mathrm{~mm}$ pode ser atribuída, principalmente, à perda de umidade $\mathrm{e}$ de material de reserva, pela transpiração e respiração respectivamente, sendo um dos principais fatores limitantes da vida útil pós-colheita de melões, sofrendo influência de inúmeros fatores, como os da cultivar, dos tratamentos pós-colheita, das condições e duração do armazenamento entre outros (Mayberry \& Hartz, 1992). Quanto maior o tempo de armazenamento maior a perda de umidade, o que resultará em perdas qualitativas e quantitativas, pois esses frutos geralmente são vendidos por unidade de massa (Souza et al., 2014).

A perda de peso além de comprometer a comercialização dos frutos em relação ao tamanho, também influenciou no brix, visto que ocorreu uma grande variação no ${ }^{\circ}$ Brix entre as lâminas de irrigação (Figura 2). Vale salientar que a perda de umidade (evapotranspiração) aumenta o consumo de açúcares (respiração), e assim diminui a qualidade do fruto. 
Figura 2. Brix dos frutos do meloeiro var. inodoro do tipo "amarelo" cultivar híbrida F1 10/00 em função das lâminas de irrigação.

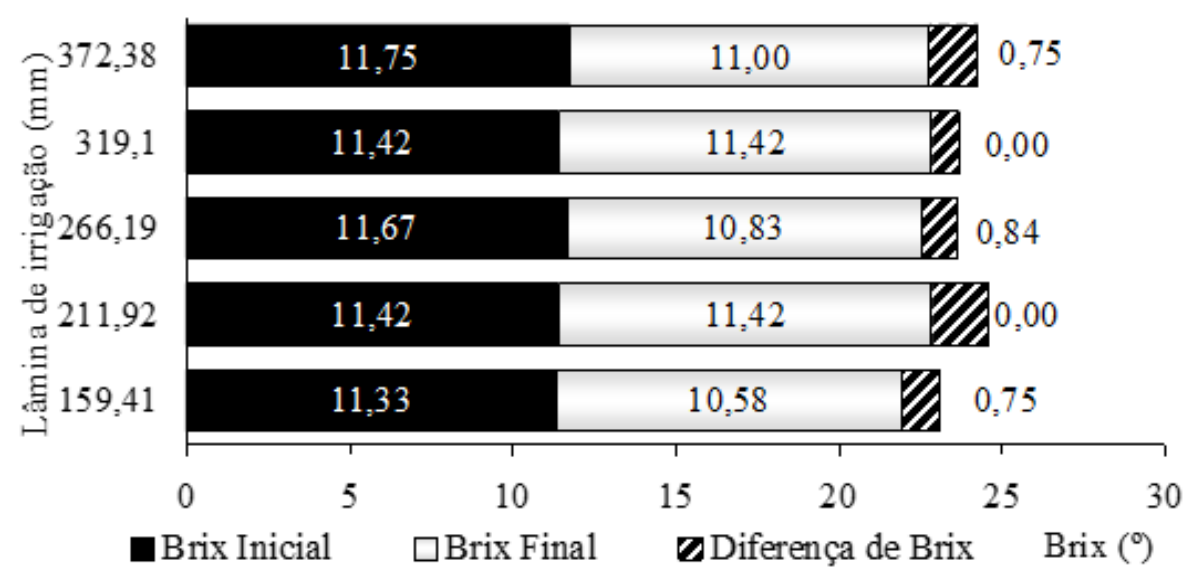

Fonte: Autores.

O teor médio de sólidos solúveis para o meloeiro foi de $11,5^{\circ}$ Brix logo após a colheita e de $11,1^{\circ}$ Brix após 30 dias de conservação em prateleira. Estes valores de sólidos solúveis observados no experimento, de acordo com Menezes et al. (2000), estão em conformidade com as exigências de mercado para a comercialização do fruto, que recomenda um valor acima de $9{ }^{\circ}$ Brix. Já Souza et al. (2014) acrescenta que o teor de sólidos solúveis é um dos padrões mais importantes na aceitação do produto pelo consumidor final, quanto maior a faixa do ${ }^{\circ}$ Brix (entre 10 e 12) maior aceitação do produto.

Os resultados observados neste trabalho estão superiores aos valores encontrados por Reis et al. (2017) que estudando as características pós-colheita do melão cultivado com lâminas de irrigação e doses de bioestimulantes observaram teores médios de sólidos solúveis de 9,4 ${ }^{\circ}$ Brix, por Souza et al. (2014) que avaliando a pós-colheita do melão amarelo submetido à danos mecânicos observaram teores médios de sólidos solúveis entre 9 e 11 Brix, e por Aroucha et al. (2012), que ao caracterizarem híbridos de melão amarelo observaram teores médios de sólidos solúveis de 9 a $9,35{ }^{\circ}$ Brix. Já Faria et al. (2015) estudando o efeito de diferentes lâminas de irrigação na qualidade de melão rendilhado em ambiente protegido observaram valores médios de $13,56^{\circ}$ Brix.

A firmeza de polpa (textura) decresceu durante o armazenamento, com uma média no início do armazenamento $(0$ dia) de 36,41 $\mathrm{N}$ e ao final (30 dias) de 13,49 N (Figura 3), verificando-se uma perda de firmeza de 63,73, 62,00, 63,91, 62,50 e $62,50 \%$ para as lâminas de 159,41,211,92,266,19, 319,10 e 372,38 mm, respectivamente, durante o tempo transcorrido. 
Figura 3. Textura dos frutos do meloeiro var. inodoro do tipo "amarelo" cultivar híbrida F1 10/00 em função das lâminas de irrigação.

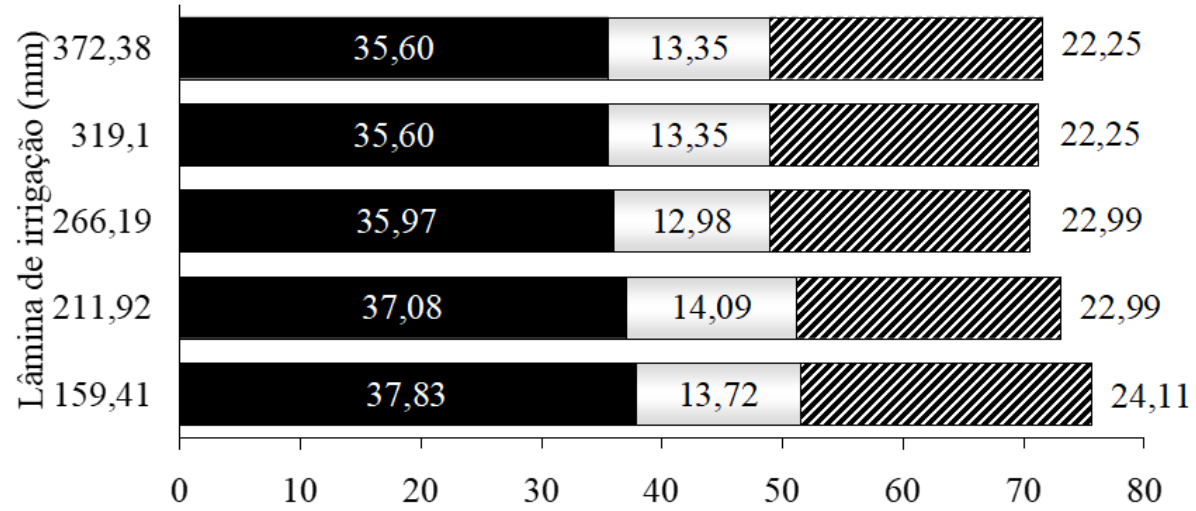

Textura inicial $\square$ Textura Final $\quad$ Diferença da textura Textura

Fonte: Autores.

Segundo Reis et al (2017), a firmeza é uma das características de qualidade que condiciona o grau de resistência a danos mecânicos e determina o tempo de conservação e vida útil de prateleira dos vegetais.

Os resultados obtidos nesta pesquisa corroboram com Pires et al. (2013) e Aragão et al. (2019) que observaram que a textura foi influenciada pelos manejos de água, obtendo-se maiores médias de firmeza nos frutos que foram submetidos à menor lâmina de água aplicada.

A perda de firmeza da polpa pode estar relacionado com o aumento da atividade de hidrolases tais como a poligalacturonase (PG) e pectinametilesterase (PME) durante o armazenamento do fruto (Menezes et al., 2000), comprovando que a perda de peso é a causa principal de deterioração no armazenamento, resultando não apenas em uma perda quantitativa, o que ocasiona sérios prejuízos econômicos, pois normalmente os frutos são vendidos por unidade de massa, mas também em uma perda qualitativa pelo enrugamento e amolecimento, dentre outros.

Para Medeiros et al. (2011), a redução de consistência da polpa está diretamente relacionada com a degradação da protopectina, um composto péctico presente na parede celular, responsável por manter a firmeza dos frutos.

\section{Conclusão}

As diferentes lâminas fornecidas no ciclo influenciaram as características de pós-colheita peso, brix e textura dos frutos, no entanto, as lâminas de irrigação causavam efeitos para mais nas características peso e brix à medida que este era aumentado, exceto para variável textura do fruto.

\section{Referências}

Colocar espaço entre uma referência e outra. Lembre-se que usamos a norma APA. (fonte TNR 8 - espaço simples -justificado)

Aragão Júnior, T. C., Magalhães, C. A. \& Santos, C. S. V. (1991). Efeitos de níveis de umidade do solo em cultivares de melão (Cucimis melo. L.). Boletim de Pesquisa 19. Fortaleza: EPACE. 16p.

Aragão, M. F., Pinheiro Neto, L. G., Aragão, M. F., Viana, T. V. A. \& Gomes, A. K. S. (2019). Efeito da cobertura do solo e da lâmina de irrigação sobre as variáveis de pós-colheita de melão amarelo. Revista Brasileira de Agricultura Irrigada, 13(6), 3749-3756. https://doi.org/10.7127/rbai.v13n6001157

Aroucha, M. M. E., Mesquita, C. H., Souza, S. M., Torres, L.W. \& Ferreira, A. M. R. (2012). Vida útil pós-colheita de cinco híbridos de melão amarelo produzidos no Agropolo Mossoró-Assu. Revista Caatinga, 25(3), 52-57.

Barros, V. S., Santos, T. L., Silva, E. O., Sousa, J. A. \& Figueirêdo, M. C. B. (2019). Agronomic and environmental performance of melon produced in the brazilian semiarid region. Revista Caatinga, 32(4), 877-888. DOI: https://doi.org/10.1590/1983-21252019v32n403rc 
Campelo, A. R., Azevedo, B. M., Nascimento Neto, J. R., Viana, T. V. A., Pinheiro Neto, L. G. \& Lima, R. H. (2014). Manejo da cultura do melão submetida a frequências de irrigação e fertirrigação com nitrogênio. Horticultura Brasileira, 32(2), 138-144. DOI: https://doi.org/10.1590/S0102-05362014000200003

Costa, M. C. (1999). Efeitos de diferentes lâminas de água com níveis de salinidade na cultura do meloeiro. Tese de Doutorado. Botucatu: UNESP, 115p.

Doorenbos, J. \& Kassam, A. H. (1994). Efeito da água no rendimento das culturas. Campina Grande: UFPB. 306p. (Estudos FAO: Irrigação e Drenagem, 33).

Doorenbos, J. \& Pruitt, W. O. (1997). Necessidades hídricas das culturas. Campina Grande: UFPB. 204p. (Estudos FAO: Irrigação e Drenagem, 24).

Embrapa - Empresa Brasileira de Pesquisa Agropecuária. (1997). Manual de métodos de análises de solo. 2.ed. Rio de Janeiro: Ministério da Agricultura e do Abastecimento. 212p.

Faria, L. A., Lima, E. M. C., Siqueira, W. C., Rezende, F. C. \& Gomes, L. A. A. (2015). Qualidade de frutos de melão rendilhado cultivado em ambiente protegido sob diferentes lâminas de irrigação. Revista Brasileira de Agricultura Irrigada, 9(6), 357-365. DOI: https://doi.org/10.7127/rbai.v9n600302

Filgueiras, H. A. C., Menezes, J. B., Alves, R. E., Costa, F. V., Pereira, L. S. E. \& Gomes Júnior, J. (2000). Colheita e manuseio pós-colheita. In: ALVES, R. E. (Org.). Melão pós-colheita. Brasília: EMBRAPA-SPI/FRUTAS DO BRASIL, 23-41. (Frutas do Brasil, 10).

Guimarães, B. R., Araújo, A. R. R., Galvão, J. R., Pacheco, M. J. B., Silva, S. B., Assis, L. F. C. T., Azevedo, J. C. \& Moraes, K. C. (2020). Melão (Cucumis melo L.): interrelações entre adubação, nutrição mineral e produção. Revista Ibero-Americana de Ciências Ambientais, 11(1), 391-399. DOI: https://doi.org/10.6008/CBPC2179-6858.2020.001.0035

Hernandez, F. B. T. (1995). Efeito da supressão hídrica nos aspectos produtivos e qualitativos da cultura do melão. Tese de Doutorado. Piracicaba: ESALQ, USP, 90p.

Mayberry, K. S. \& Hartz, T. K. (1992). Extension of muskmelon storage life through the use of hot water treatment and polyethylene wraps. Hortscience, 27(4), 324-326.

McCollum, T. G., Huber, D. J. \& Cantliffe, D. J. (1989). Modification of polyuronides and hemicelluloses during muskmelon fruit softening. Physiologia Plantarum, 76(3), 303-309. DOI: https://doi.org/10.1111/j.1399-3054.1989.tb06195.x

Medeiros, C. D., Medeiros, F. J., Pereira, L. A. F., Souza, O. R. \& Souza, A. P. (2011). Produção e qualidade de melão cantaloupe cultivado com água de diferentes níveis de salinidade. Revista Caatinga, 24(1), 92-98.

Melo, T. K., Medeiros, J. F., Espínola Sobrinho, J., Figueirêdo, V. B., Pereira, V. C. \& Campos, M. S. (2011). Evapotranspiração e produção do melão Gália irrigado com água de diferentes salinidades e adubação nitrogenada. Revista Brasileira de Engenharia Agrícola e Ambiental, 15(12), 1235-1242. DOI: https://doi.org/10.1590/S1415-43662011001200004

Mendonça, F. V. S., Menezes, J. B., Guimarães, A. A., Souza, P. A., Simões, A. N. \& Souza, G. L. F. M. (2004). Armazenamento do melão amarelo, híbrido RX20094, sob temperatura ambiente. Horticultura Brasileira, 22(1), 76-79. https://doi.org/10.1590/S0102-05362004000100015

Menezes, J. B., Filgueiras, H. A. C., Alves, R. E., Maia, C. E., Andrade, C. E., Andrade, G. G., Almeida, J. H. S. \& Viana, F. M. P. (2000). Características do melão para exportação. In: Alves, R. E. (Org.). Melão: pós-colheita. Brasília, DF: Embrapa Comunicação para Transferência de Tecnologia; Fortaleza: Embrapa Agroindústria Tropical, 2000. (Frutas do Brasil, 10).

Pereira, F. A. L., Medeiros, J. F., Gheyi, H. R., Dias, N. S., Preston, W. \& Vasconcelos, C. B. L. (2017). Tolerance of melon cultivars to irrigation water salinity. Revista Brasileira de Engenharia Agrícola e Ambiental, 21(12), 846-851. DOI: https://doi.org/10.1590/1807-1929/agriambi.v21n12p846-851

Pereira, W. B., Possídio, C. E. F., Sousa, J. S. C., Simões, W. L. \& Santos, C. M. G. (2021). Produção e Qualidade de Melões Sob Diferentes Arranjos do Sistema de Irrigação e Coberturas do Solo. Revista Brasileira de Meteorologia, 36(2), 285-294. DOI: http://dx.doi.org/10.1590/0102-77863620121

Pinto, M. M. F., Gonçalves, J. S., Souza, I. T. N., Batista, N. V., Melo, V. L. L., Firmino, S. S., Pinedo, L. Á. \& Lima, P. O. (2019). Utilização do melão (Cucumis melo L.) na alimentação de ruminantes: uma revisão. Brazilian Journal of Development, 5(12), 31466-31481. DOI: https://doi.org/10.34117/bjdv5n12-240

Pires, M. M. M. L., Santos, H. A., Santos, D. F., Vasconcelos, A. S. \& Aragão, C. A. (2013). Produção do meloeiro submetido a diferentes manejos de água com o uso de manta de tecido não tecido. Horticultura Brasileira, 31(2), 304-310. DOI: https://doi.org/10.1590/S0102-05362013000200021

Queiroga, R. C. F., Silva, Z. L., Oliveira, O. H., Santos, E. N., Silva, H. L. O, Costa, F. B. \& Assis, L. E. (2020). Melon fruit yield and quality as a function of doses and times of biostimulant application. Research, Society and Development. 9(7):1-18. e130973911. DOI: http://dx.doi.org/10.33448/rsd-v9i7.3911

Reis, D. S., Simões, W. L., Silva, J. A. B., Gomes, V. H. F., Nascimento, M., Silva, E. P. \& Alberto, K. C. (2017). Pós-colheita do melão cultivo com lâminas de irrigação e doses bioestimulante em Juazeiro, BA. Anais... In: Jornada de Integração da Pós-Graduação da Embrapa Semiárido, 2, Petrolina: Embrapa Semiárido, 2017

Richards, L. A., Gardner, W. R. \& Ogata, G. (1956). Physical processes determining water loss from soil. Soil Science Society of America Journal, 20(3), 310314. DOI: https://doi.org/10.2136/sssaj1956.03615995002000030004x

Simões, W. L., Sousa, J. S. C., Salviano, A. M., Calgaro, M. \& Gomes, V. H. F. (2018). Produção do meloeiro sob diferentes lâminas de irrigação e doses de bioestimulante no Submédio São Francisco. Anais... In: Congresso Internacional das Ciências Agrárias, 3. 2018, Teresina: COINTER PDVAgro, 2018.

Souza, M. H. C., Silva, M. V. T., Vasconcelos, O. C. M., Oliveira, F. L. \& Figueiredo Neto, A. (2014). Avaliação pós-colheita do melão amarelo submetido danos mecânicos. Revista Verde, 9(4), 195-200.

Thornthwaite, C. W. \& Mather, J. R. (1955). The water balance. Centerton, NJ: Drexel Institute of Technology - Laboratory of Climatology. 8(1), 104p.

Valnir Júnior, M., Lima, V. L. A., Gomes Filho, R. R., Carvalho, C. M., Soares, F. A. L. \& Lima, S. C. R. V. (2013). Lâminas de irrigação e frequência de aplicação no crescimento do meloeiro. Revista Brasileira de Agricultura Irrigada, 7(1), 42-53. DOI: http://dx.doi.org/10.7127/rbai.v7n100102 